\title{
Ordered-defect sulfides as thermoelectric materials
}

Article

Accepted Version

Kaltzoglou, A., Vaqueiro, P., Barbier, T., Guilmeau, E. and Powell, A. V. (2014) Ordered-defect sulfides as thermoelectric materials. Journal of Electronic Materials, 43 (6). pp. 20292034. ISSN 1543-186x doi: https://doi.org/10.1007/s11664013-2941-0 Available at https://centaur.reading.ac.uk/37395/

It is advisable to refer to the publisher's version if you intend to cite from the work. See Guidance on citing.

Published version at: http://link.springer.com/article/10.1007/s11664-013-2941-0

To link to this article DOI: http://dx.doi.org/10.1007/s11664-013-2941-0

Publisher: Minerals, Metals and Materials Society

Publisher statement: (c) 2014 IEEE. Personal use of this material is permitted. Permission from IEEE must be obtained for all other users, including reprinting/ republishing this material for advertising or promotional purposes, creating new collective works for resale or redistribution to servers or lists, or reuse of any copyrighted components of this work in other works.

All outputs in CentAUR are protected by Intellectual Property Rights law, including copyright law. Copyright and IPR is retained by the creators or other copyright holders. Terms and conditions for use of this material are defined in the End User Agreement. 


\section{CentAUR}

Central Archive at the University of Reading

Reading's research outputs online 


\title{
Ordered-defect sulphides as thermoelectric materials
}

\author{
Andreas Kaltzoglou ${ }^{1,3}$, Paz Vaqueiro ${ }^{1,3}$, Tristan Barbier $^{2}$, Emmanuel Guilmeau ${ }^{2}$, \\ Anthony V. Powell ${ }^{1,3, *}$ \\ ${ }^{1}$ Institute of Chemical Sciences, Heriot-Watt University, Edinburgh EH14 4AS, \\ United Kingdom \\ ${ }^{2}$ Laboratoire CRISMAT, UMR 6508 CNRS/ENSICAEN, 6 bd du Maréchal Juin, \\ F-14050 CAEN Cedex 4, France \\ ${ }^{3}$ Present address: Department of Chemistry, University of Reading, Whiteknights, \\ Reading RG6 6AD, United Kingdom
}

*Corresponding author: a.v.powell@ reading.ac.uk

The thermoelectric behaviour of the transition-metal disulphides $n$-type $\mathrm{NiCr}_{2} \mathrm{~S}_{4}$ and $p$-type $\mathrm{CuCrS}_{2}$ is investigated. Materials prepared by high-temperature reaction were consolidated using cold-pressing and sintering, hot-pressing (HP) in graphite dies or spark-plasma sintering (SPS) in tungsten carbide dies. The consolidation conditions have a marked influence on the electrical transport properties. In addition to the effect on sample density, altering the consolidation conditions results in changes to the sample composition, including the formation of impurity phases. Maximum room-temperature power factors are $0.18 \mathrm{~mW} \mathrm{~m}^{-1} \mathrm{~K}^{-2}$ and $0.09 \mathrm{~mW} \mathrm{~m}^{-1} \mathrm{~K}^{-2}$ for $\mathrm{NiCr}_{2} \mathrm{~S}_{4}$ and $\mathrm{CuCrS}_{2}$, respectively. Thermal conductivities of $c a .1 .4$ and $1.2 \mathrm{~W} \mathrm{~m}^{-1} \mathrm{~K}^{-1}$ lead to figures of merit of 0.024 and 0.023 for $\mathrm{NiCr}_{2} \mathrm{~S}_{4}$ and $\mathrm{CuCrS}_{2}$, respectively.

Keywords Thermoelectric properties, transition metal sulphides, hot pressing, spark plasma sintering, consolidation methods

\section{Introduction}

Thermoelectric materials are of increasing interest for applications involving energy harvesting from waste heat. The efficiency of a thermoelectric device is dependent on the physical properties of the component materials. In particular, the thermoelectric performance of a material is dependent on an unusual combination of high electrical conductivity $(\sigma)$, typically found in metals, together with a low thermal conductivity $(\kappa)$ and high Seebeck coefficient (S), characteristics more usually associated with non-metallic systems, and is embodied in the dimensionless figure of merit, $\mathrm{ZT}=\mathrm{S}^{2} \sigma \mathrm{T} / \mathrm{\kappa}$ [1]. Recently, there has been renewed interest in sulphide-based 
thermoelectrics and the potential they offer for low-cost alternatives to the current commercial material of choice, $\mathrm{Bi}_{2} \mathrm{Te}_{3}$.

In the search for sulphide-based thermoelectrics, we have recently begun to investigate the potential of ordered-defect phases. These materials comprise two-dimensional dichalcogenide slabs of edge-sharing octahedra stacked in a direction perpendicular to the slab direction. The van der Waals' gap between adjacent slabs consists of a network of vacant octahedral and tetrahedral sites. Partial occupancy of such sites by cations in phases, $A_{\mathrm{x}} M \mathrm{~S}_{2}$, may occur in an ordered fashion giving rises to a range of two-dimensional superstructures [2], some of which are stable over a range of $\mathrm{x}$. The nature of the cation ordering is also temperature dependent and order-disorder transitions are commonly observed at elevated temperatures [3,4,5]. Ordered-defect phases are attractive candidates for thermoelectrics as they combine low-dimensionality, intrinsic to the dichalcogenide slab, with the capacity to tune electron-transport properties through chemical substitution. For example, substitution of vanadium for chromium in $\mathrm{NiCr}_{2} \mathrm{~S}_{4}\left(\mathrm{Ni}_{0.5} \mathrm{CrS}_{2}\right)$ effects a semiconductor to metal transition at a critical level of substitution, $\mathrm{x}_{\mathrm{c}} \approx 0.4[6,7]$.

Here, we present a preliminary investigation of the thermoelectric properties of $\mathrm{NiCr}_{2} \mathrm{~S}_{4}$ and $\mathrm{CuCrS}_{2}$ which each contain $\mathrm{CrS}_{2}$ slabs. The former adopts a monoclinic structure at room temperature [8] in which $50 \%$ of the octahedral sites between pairs of dichalcogenide slabs are occupied by cations (Fig 1(a)). At room temperature $\mathrm{CuCrS}_{2}$ adopts a trigonal structure [9] in which $50 \%$ of tetrahedral sites are occupied between pairs of $\mathrm{CrS}_{2}$ slabs (Fig 1(b)). Our previous measurements of the electrical transport properties of cold-pressed and sintered samples of $\mathrm{NiCr}_{2} \mathrm{~S}_{4}$ reveal $n$-type semiconducting behavior and lead to determination of the thermoelectric power factor as ca. $0.1 \mathrm{~mW} \mathrm{~m}^{-1} \mathrm{~K}^{-2}$ at room temperature [10]. However, to the best of our knowledge, the thermal conductivity of this phase has not been determined. The thermoelectric properties of $p$-type $\mathrm{CuCrS}_{2}$ have been the subject of considerable recent interest following the report of a figure of merit as high as 2.0 at room temperature [11,12]. The performance of this material appears to be sensitive to the thermal history of the sample. Extended sintering at high temperatures $\left(850-900{ }^{\circ} \mathrm{C}\right)$ followed by quenching in air appears to be required for optimum properties, as it promotes copper-ion disorder, thereby reducing the thermal conductivity, and leads to increased texture of the sample, which increases the electrical conductivity. However, recent work by another group has shown that SPS processed samples exhibit a much higher electrical resistivity than previously reported and the maximum figure of merit, $Z \mathrm{~T}=0.11$, is 
observed at $400{ }^{\circ} \mathrm{C}$ [13]. At higher temperatures volatilization of sulphur was observed leading to a reduced charge-carrier concentration and a transition from $p$ - to $n$-type conductivity.

In this work, we describe an investigation of the impact of the consolidation method on the thermoelectric properties of $\mathrm{NiCr}_{2} \mathrm{~S}_{4}$ and $\mathrm{CuCrS}_{2}$. The results demonstrate that the consolidation method has a marked effect on materials' properties through grain growth, which manifests itself in differences in the degree of densification and through changes in the chemical composition of the sample, including the formation of impurity phases, which can produce variations in the electrical transport properties by up to an order of magnitude and even induce a change in the dominant charge carriers from electrons to holes.

a)

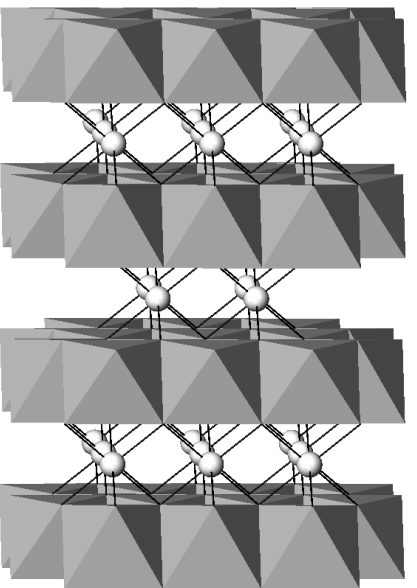

b)

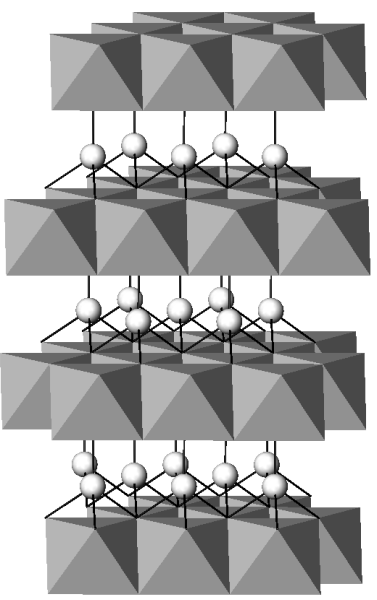

Fig.1 Crystal structure of a) $\mathrm{NiCr}_{2} \mathrm{~S}_{4}$ and b) $\mathrm{CuCrS}_{2}$ with $\mathrm{Ni}$ and $\mathrm{Cu}$ atoms (open circles) partially filling octahedral and tetrahedral gaps, respectively, between edge-sharing $\mathrm{CrS}_{6}$ octahedra (grey).

\section{Experimental}

Materials were synthesized by reaction of appropriate mixtures of the elements (Ni (Aldrich, 99.9\%), $\mathrm{Cu}$ (Aldrich, 99.5\%), $\mathrm{Cr}$ (Aldrich, 99+\%) and $\mathrm{S}$ (Aldrich, 99.99+\%)) at high temperatures in evacuated $\left(<10^{-4}\right.$ Torr) silica tubes. In the case of the nickel-containing phase, a reaction mixture slightly deficient in sulphur was used, corresponding to a composition, $\mathrm{NiCr}_{2} \mathrm{~S}_{3.93}$, whereas that for the copper-containing materials the reaction mixture was stoichiometric. $\mathrm{NiCr}_{2} \mathrm{~S}_{4}$ was heated at $900{ }^{\circ} \mathrm{C}$ for 1 day before annealing at $500{ }^{\circ} \mathrm{C}$ for 5 hours whilst $\mathrm{CuCrS}_{2}$ was heated at $500{ }^{\circ} \mathrm{C}$ for 12 hours. $\mathrm{CuCrS}_{2}$ was also synthesised by mechanical alloying (MA) in a PM100 Retsch planetary ball mill, using a steel jar and grinding balls at $650 \mathrm{rpm}$ for 24 hours. Powder Xray diffraction data for all materials were collected using a Bruker D8 Advance powder diffractometer, operating with $\mathrm{Ge}$-monochromated $\mathrm{Cu} K_{\alpha 1}$ radiation $(\lambda=1.5406 \AA)$ and equipped 
with a LynxEye linear detector. Rietveld refinements were performed using the GSAS software package [14].

With the exception of one batch of $\mathrm{NiCr}_{2} \mathrm{~S}_{4}$ that was micronized by ball milling ( $1 \mathrm{~h}$ at $400 \mathrm{rpm}$ ) and the sample of $\mathrm{CuCrS}_{2}$ made by mechanical alloying, all materials were ground to a fine powder in an agate mortar prior to consolidation. Powdered samples were consolidated by coldpressing at $750 \mathrm{MPa}$ in a stainless steel die followed by sintering for four days at $800{ }^{\circ} \mathrm{C}$ in an evacuated sealed silica; by hot-pressing (HP) in graphite die for 30 minutes under a $\mathrm{N}_{2}$ atmosphere at various temperatures and pressures; and by spark-plasma sintering (SPS) on an FCT instrument using tungsten carbide dies under $300 \mathrm{MPa}$ and at various temperatures. Details of temperatures and pressures are provided in the results section. Sulphur analysis for selected samples was carried out by inductively coupled plasma-atomic emission spectroscopy (Exeter Analytical (UK)).

Rectangular ingots with approximate dimensions of $2 \times 2 \times 10 \mathrm{~mm}^{3}$ were cut from the compacted pellets and polished with fine sandpaper. The electrical resistivity (4-probe DC) and Seebeck coefficient of the ingots were determined over the temperature range $40 \leq \mathrm{T} /{ }^{\circ} \mathrm{C} \leq 300$ under a static He atmosphere of 1.1 - 1.4 bar using a Linseis LSR-3 instrument. Corresponding data for $\mathrm{NiCr}_{2} \mathrm{~S}_{4}$ consolidated by SPS were obtained over the temperature range $30 \leq \mathrm{T} /{ }^{\circ} \mathrm{C} \leq 300$ using an Ulvac ZEM-3 instrument. The thermal conductivity of $\mathrm{NiCr}_{2} \mathrm{~S}_{4}$ at room temperature was measured using a TPS 2500s instrument, whereas that of $\mathrm{CuCrS}_{2}$ was determined using a Quantum Design Physical Property Measurement System.

\section{Results and Discussion}

\section{Materials characterization}

Rietveld analysis of powder X-ray diffraction data confirms that all reaction products are phase pure materials. Powder diffraction data for $\mathrm{NiCr}_{2} \mathrm{~S}_{4}$ are well described (Fig. 2) by a monoclinic structural model involving complete ordering of $\mathrm{Ni}$ and $\mathrm{Cr}$ over octahedral sites. It was not possible to refine the sulphur content, owing to the small deviation from stoichiometry. Rietveld refinement using powder $\mathrm{X}$-ray diffraction data collected for $\mathrm{CuCrS}_{2}$ (Fig. 3), reveals that $\mathrm{Cu}$ and $\mathrm{Cr}$ atoms are fully ordered in tetrahedral and octahedral sites respectively.

The density of the consolidated samples of $\mathrm{NiCr}_{2} \mathrm{~S}_{4}$ increases with increasing consolidation temperature and pressure (Table 1), reaching ca. $99 \%$ of the crystallographic density when 
processed by SPS $\left(650^{\circ} \mathrm{C}, 300 \mathrm{MPa}\right)$. Notably, powder X-ray diffraction data for consolidated samples reveals $c a .5 \mathrm{wt} \%$ of $\mathrm{NiS}_{2}$ impurity in the samples consolidated by $\mathrm{HP}$ at $100 \mathrm{MPa}$ and by SPS at $300 \mathrm{MPa}$. The presence of $\mathrm{NiS}_{2}$ is consistent with an increased sulphur content determined by elemental analysis of the sample processed by HP at $100 \mathrm{MPa}$. The absence of any chromiumcontaining decomposition products in powder X-ray diffraction data suggests that this phase can tolerate a degree of non-stoichiometry on the nickel and sulphur sub-lattices. The sample processed by $\mathrm{HP}$ at $600{ }^{\circ} \mathrm{C}, 60 \mathrm{MPa}$ exhibits a sulphur content slightly lower than that expected from the reaction stoichiometry, suggesting some volatilization may occur under these conditions.

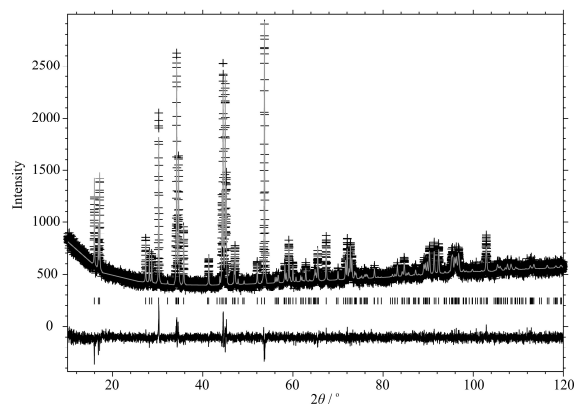

Fig. 2 Final observed (crosses), calculated (solid line) and difference (full lower line) profiles from Rietveld refinements for $\mathrm{NiCr}_{2} \mathrm{~S}_{4}$ using powder X-ray diffraction data (Space group: $I 2 / m, a=$ 5.91128(8), $\left.b=3.41042(5), c=11.1094(1) \AA, \beta=91.163(1)^{\mathrm{o}} ; R_{\mathrm{wp}}=4.90 \%, \chi^{2}=1.26\right)$

a)

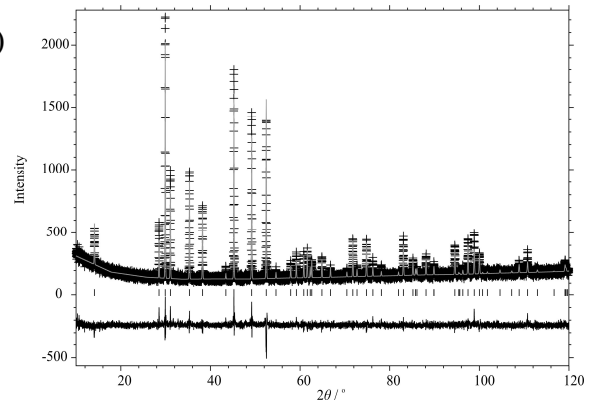

b)

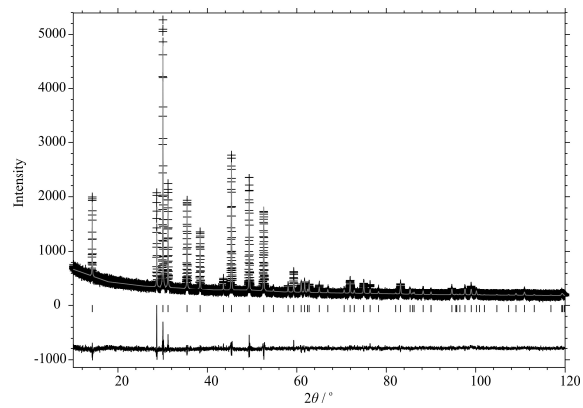

Fig. 3 Final observed (crosses), calculated (solid line) and difference (full lower line) profiles from Rietveld refinements for (a) as-synthesized $\mathrm{CuCrS}_{2}$ using powder X-ray diffraction data. (Space Group: $R 3, a=3.47962(2) \AA, c=18.6927(2) \AA, R_{\mathrm{wp}}=8.63 \%, \chi^{2}=1.37$ ) and (b) for cold-pressed and sintered $\mathrm{CuCrS}_{2}$ illustrating the change in reflection intensities due to texturing. (Space Group: $\left.R 3, a=3.48038(3) \AA, c=18.6969(2) \AA, R_{\mathrm{wp}}=7.36 \%, \chi^{2}=1.63\right)$

The density of the consolidated samples of $\mathrm{CuCrS}_{2}$ ranges from $89 \%$ to $97 \%$ of the crystallographic value (Table 2). Under the same hot-pressing conditions, the density of the MA sample is slightly higher than for the sample obtained by conventional reaction. Powder X-ray diffraction indicates no sample decomposition occurs under any of the consolidation conditions investigated. However, powder X-ray diffraction data for the sample produced by cold-pressing exhibit a marked increase in the intensity of (00l) reflections (Fig. 3 (b)), suggesting preferred 
orientation due to texturing. This is consistent with previous reports [11], which suggest that texturing occurs on prolonged high-temperature sintering followed by fast quenching of the polycrystalline solid.

Table 1. Consolidation conditions and bulk characteristics for $\mathrm{NiCr}_{2} \mathrm{~S}_{4}$ samples.

\begin{tabular}{|c|c|c|c|c|}
\hline $\begin{array}{l}\text { Consolidation } \\
\text { conditions }\end{array}$ & Code & $\begin{array}{c}\text { Density } \\
\left(\mathrm{g} \mathrm{cm}^{-3}\right)\end{array}$ & $\begin{array}{c}\text { S content }{ }^{[3]} \\
(\mathrm{wt} \%)\end{array}$ & Impurity phases \\
\hline $\mathrm{HP}$ at $600{ }^{\circ} \mathrm{C} / 60 \mathrm{MPa}$ & $1 \mathrm{a}$ & 3.31 & 43.52 & None detected \\
\hline $\mathrm{HP}$ at $600^{\circ} \mathrm{C} / 110 \mathrm{MPa}$ & $2 \mathrm{a}$ & 3.61 & 45.15 & $\mathrm{NiS}_{2}$ \\
\hline $\mathrm{HP}$ at $600{ }^{\circ} \mathrm{C} / 60 \mathrm{MPa}^{[1]}$ & $3 \mathrm{a}$ & 3.16 & 一 & None detected \\
\hline $\mathrm{HP}$ at $680^{\circ} \mathrm{C} / 60 \mathrm{MPa}$ & $4 a$ & 3.68 & - & None detected \\
\hline $\mathrm{HP}$ at $800^{\circ} \mathrm{C} / 60 \mathrm{MPa}$ & $5 a$ & 3.72 & - & None detected \\
\hline SPS at $600{ }^{\circ} \mathrm{C} / 300 \mathrm{MPa}$ & $6 \mathrm{a}$ & 4.18 & 一 & $\mathrm{NiS}_{2}$ detected \\
\hline SPS at $650{ }^{\circ} \mathrm{C} / 300 \mathrm{MPa}$ & $7 \mathrm{a}$ & 4.27 & - & $\mathrm{NiS}_{2}$ detected \\
\hline
\end{tabular}

[1] Powder ball milling at $400 \mathrm{rpm}$ for 1 hour prior to hot pressing

[2] Crystallographic density: $d=4.31 \mathrm{~g} \mathrm{~cm}^{-3}$

[3] $43.65 \mathrm{wt} \% \mathrm{~S}$ content expected for $\mathrm{NiCr}_{2} \mathrm{~S}_{3.93}$ and $44.08 \mathrm{wt} \%$ for $\mathrm{NiCr}_{2} \mathrm{~S}_{4}$

Table 2. Consolidation conditions and density for $\mathrm{CuCrS}_{2}$ samples.

\begin{tabular}{lcc}
\hline \multicolumn{1}{c}{ Consolidation conditions } & Code & $\begin{array}{c}\text { Density } \\
\left(\mathrm{g} \mathrm{cm}^{-3}\right)\end{array}$ \\
\hline Cold pressing at $700 \mathrm{MPa}$, sintered & $1 \mathrm{~b}$ & 4.06 \\
4d at $850{ }^{\circ} \mathrm{C}$ quenched & $2 \mathrm{~b}$ & 4.15 \\
Hot pressing at $600{ }^{\circ} \mathrm{C}, 60 \mathrm{MPa}$ & $3 \mathrm{~b}$ & 4.23 \\
Hot pressing at $600^{\circ} \mathrm{C}, 60 \mathrm{MPa}^{[1]}$ & $4 \mathrm{~b}$ & 4.44 \\
\hline
\end{tabular}

[1] Obtained by mechanical alloying

[2] Crystallographic density: $d=4.56 \mathrm{~g} \mathrm{~cm}^{-3}$

\section{Physical properties}

The electrical resistivity and Seebeck coefficient data for $\mathrm{NiCr}_{2} \mathrm{~S}_{4}$ (Fig. 4) reveal a marked dependence of the electrical transport properties on the consolidation method. Whilst electrons are the dominant charge carriers in all consolidated materials, the resistivity of HP samples changes from a semiconducting to a metallic-like temperature dependence with increasing density, whereas the two SPS processed samples exhibit semiconducting behaviour. The Seebeck coefficient at 40 ${ }^{\circ} \mathrm{C}$ ranges from -18 to $-172 \mu \mathrm{V} \mathrm{K}^{-1}$ depending on the processing method. For the SPS processed samples, the absolute value of the Seebeck coefficient decreases with increasing temperature, whereas for most of the hot-pressed samples Seebeck coefficient increases in absolute value with increasing temperature. The temperature dependence of the electrical resistivity and the Seebeck coefficient of the hot-pressed samples is characteristic of conduction by extrinsic charge carriers, and indicate that these samples behave as degenerate semiconductors. The highest power factor of $0.18 \mathrm{~mW} \mathrm{~m}^{-1} \mathrm{~K}^{-2}$ at room temperature is reached for the material processed by SPS at $650{ }^{\circ} \mathrm{C}, 300$ 
$\mathrm{MPa}$ and is higher than that determined in our previous report on cold-pressed and sintered pellets [10]. The difference may be attributed to the lower relative density ( $c$. $75 \%$ ) of the latter material, which leads to an increase in the electrical resistance (by a factor of 2) over the SPS processed sample. The thermal conductivity of $\mathrm{NiCr}_{2} \mathrm{~S}_{4}$ processed by $\mathrm{HP}$ at $680{ }^{\circ} \mathrm{C}, 60 \mathrm{MPa}$ was determined as $1.4 \mathrm{~W} \mathrm{~m}^{-1} \mathrm{~K}^{-1}$ at $40{ }^{\circ} \mathrm{C}$, leading to a figure of merit, $Z T \approx 0.024$.

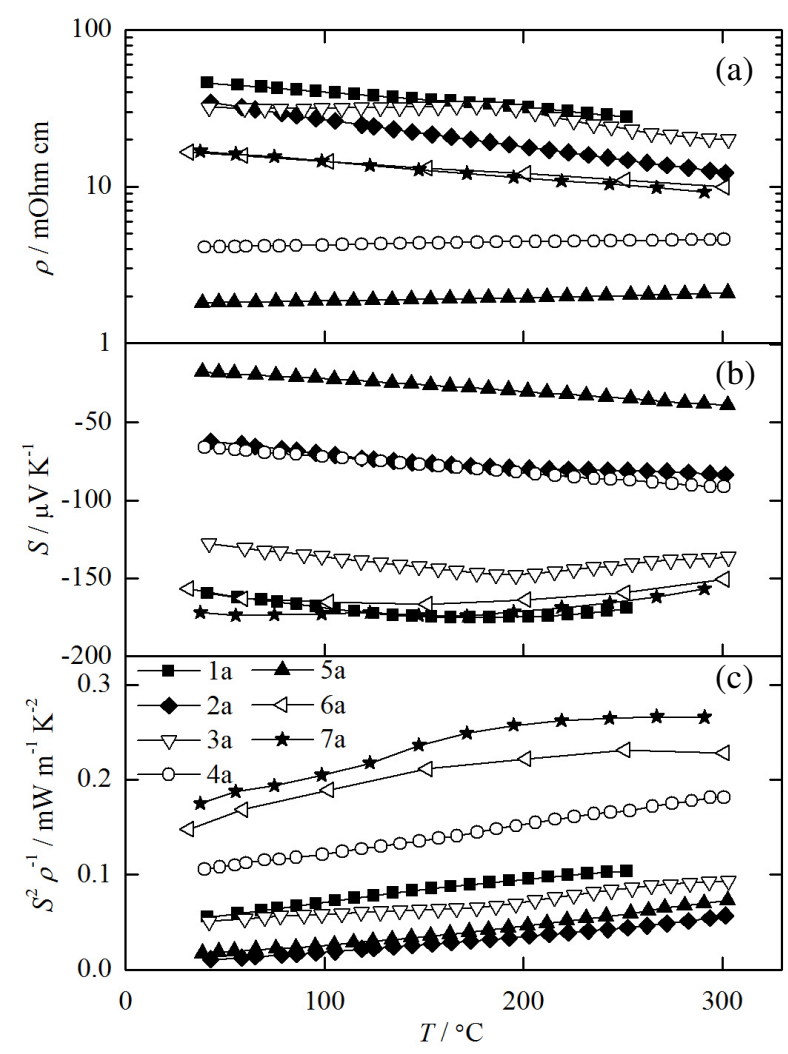

Fig. 4 Thermoelectric properties of $\mathrm{NiCr}_{2} \mathrm{~S}_{4}$ over the temperature range $30 \leq T /{ }^{\circ} \mathrm{C} \leq 300$ (a) electrical resistivity in logarithmic scale (b) Seebeck coefficient and (c) power factor.

All consolidated samples of $\mathrm{CuCrS}_{2}$ behave as $p$-type semiconductors (Fig. 5). The Seebeck coefficient of HP samples, show an almost linear increase with temperature whereas in the coldpressed and sintered sample the value is almost temperature independent. In the latter case, a power factor of $0.09 \mathrm{~mW} \mathrm{~m}^{-1} \mathrm{~K}^{-2}$ and thermal conductivity measured as $\kappa\left(40{ }^{\circ} \mathrm{C}\right) \approx 1.2 \mathrm{~W} \mathrm{~m}^{-1} \mathrm{~K}^{-1}$ lead to $Z T \approx 0.023$ at room temperature. This performance is much lower than that in the original report by Tewari et al $\left(\rho=6 \mathrm{mOhm} \mathrm{cm}, S=445 \mu \mathrm{V} \mathrm{K}^{-1}, \kappa=0.48 \mathrm{~W} \mathrm{~m}^{-1} \mathrm{~K}^{-1}\right.$ and $Z T=2$ at room temperature) [11] but is in good agreement with a large number of literature reports on the thermoelectric properties of this phase $[13,15,16,17]$. The principal origin of the discrepancy is believed to be the strong anisotropy in the cold-pressed and sintered sample [9]. The bond strength between $\mathrm{Cu}$ cations in the van der Waals' gap and $\mathrm{S}$ anions in the $\mathrm{CrS}_{2}$ slabs has a significant 
effect on the $\mathrm{Cu}^{+}$ionic conductivity [18]. The increase in unit cell volume upon prolonged sintering, observed here [19] and in a previous study where the $c$ parameter increases upon sintering at $900^{\circ} \mathrm{C}$ for 8 days [9], may be indicative of a weakening of this bonding and increased mobility of $\mathrm{Cu}^{+}$species. The formation on consolidation of point defects associated with the copper ion sub-lattice, may also influence the electrical properties [20], although if present, these are at too low a level to be detected in Rietveld refinement using powder X-ray diffraction data.

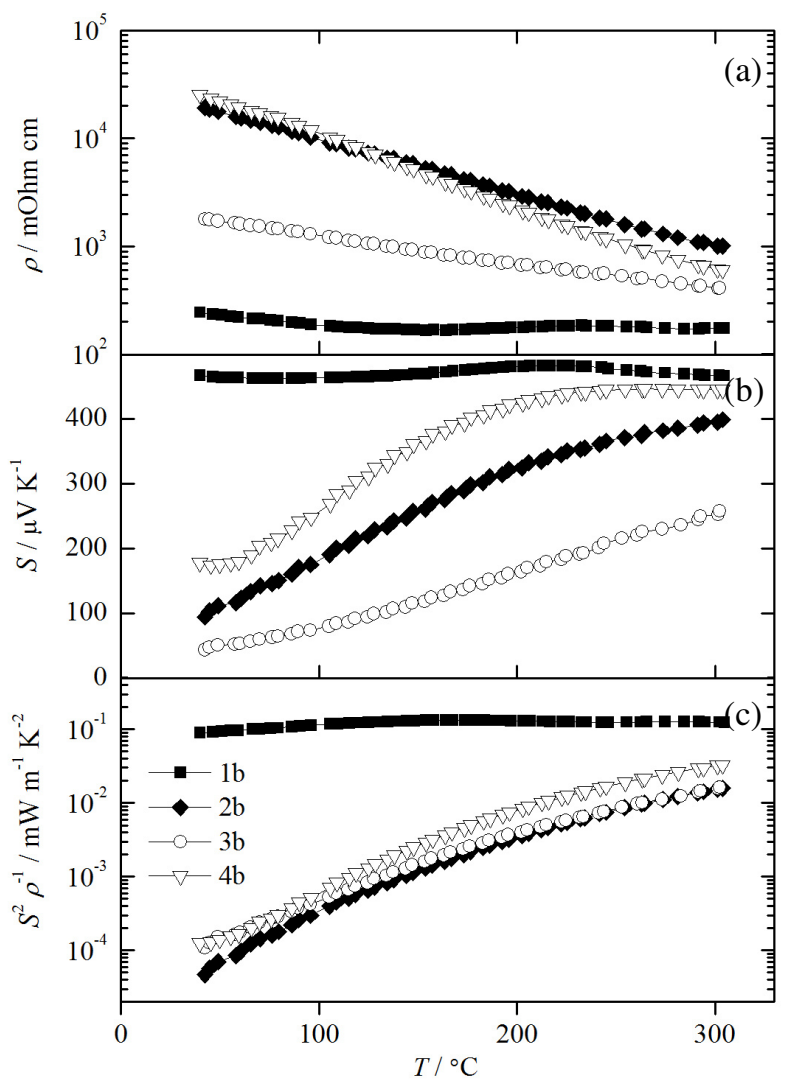

Fig. 5 Thermoelectric properties of $\mathrm{CuCrS}_{2}$ over the temperature range $40 \leq T /{ }^{\circ} \mathrm{C} \leq 300$ (a) electrical resistivity in logarithmic scale (b) Seebeck coefficient and (c) power factor.

\section{Conclusions}

Both $\mathrm{NiCr}_{2} \mathrm{~S}_{4}$ and $\mathrm{CuCrS}_{2}$ exhibit a modest thermoelectric response. The highest measured power factor of $0.27 \mathrm{~mW} \mathrm{~m} \mathrm{~K}^{-1}$ at $267{ }^{\circ} \mathrm{C}$ for the SPS-processed sample of $\mathrm{NiCr}_{2} \mathrm{~S}_{4}$ is considerably lower than for the best $n$-type materials such as the skutterudite $\mathrm{Yb}_{0.19} \mathrm{Co}_{4} \mathrm{Sb}_{12}[21$, 22], which exhibits a power factor of up to $4 \mathrm{~mW} \mathrm{~m}^{-1} \mathrm{~K}^{-2}$ at $300{ }^{\circ} \mathrm{C}$. However, there is considerable scope for tuning the thermoelectric properties of ordered-defect phases through chemical substitution, to which such materials are particularly amenable. The work reported here 
also demonstrates that the consolidation process may have a marked effect on the thermoelectric properties of $\mathrm{NiCr}_{2} \mathrm{~S}_{4}$ and $\mathrm{CuCrS}_{2}$. Variations in electron-transport properties of up to an order of magnitude are observed depending on the consolidation conditions used. In addition to changes in sample composition that are evidenced by powder X-ray diffraction, variations in sample density occur. These are likely to reflect changes in the microstructure of the materials involving differences in grain growth and grain boundary formation. Detailed examination by microscopy techniques are required to characterise such changes at the microstructural level.

\section{Acknowledgements}

Financial support by the European Commission (FP7-SME-2012-1, Grant Agreement no. 315019) is gratefully acknowledged. We wish to thank Drs. Lars Hälldahl, K-Analys AB, Sweden and Ramzy Daou, Laboratoire CRISMAT, France for thermal conductivity measurements.

\section{References}

${ }^{1}$ J.R. Sootsman, D.Y. Chung, M.G. Kanatzidis, Angew. Chem. Inter. Ed. 48, 8616 (2009)

${ }^{2}$ P. Vaqueiro, A.V. Powell, Chem. Mater. 12, 2705 (2000)

${ }^{3}$ P. Vaqueiro, S. Hull, B. Lebech, A.V. Powell, J. Mater. Chem. 9, 2859 (1999)

${ }^{4}$ P. Vaqueiro, A.V. Powell, B. Lebech, Physica B 276, 238 (2000)

${ }^{5}$ I.G. Vassilieva, T.Yu. Kardash, V.V. Malakhov, J. Struct. Chem. 50, 288 (2009)

${ }^{6}$ R.J. Bouchard, A Wold, J. Phys. Chem. Solids 27, 591 (1966)

${ }^{7}$ A.V. Powell, P. Vaqueiro, A. McDowall, Solid State Ionics 172, 469 (2004)

${ }^{8}$ A.V. Powell, D.C. Colgan, C. Ritter, J. Solid State Chem. 134, 110 (1997)

${ }^{9}$ G.C. Tewari, T.S. Tripathi, A.K. Rastogi, Z. Kristallogr. 225, 471 (2010)

${ }^{10}$ A.V. Powell, P. Vaqueiro, T. Ohtani, Phys. Rev. B 71, 125120 (2005)

${ }^{11}$ G.C. Tewari, T.S. Tripathi, A.K. Rastogi, J. Elec. Mat. 39, 1133 (2010)

${ }^{12}$ G.C. Tewari, T.S. Tripathi, P. Kumar, A.K. Rastogi, S.K. Pasha, G. Gupta, J. Elec. Mat. 40, $2368(2011)$

${ }^{13}$ Y.-X. Chen, B.-P. Zhang, Z.-H. Ge, P.-P. Shang, J. Solid State Chem. 186, 109 (2012)

${ }^{14}$ A.C. Larson, R.B. von Dreele, General Structure Analysis System, Los Alamos Laboratory, [Report LAUR 85-748] (1994)

${ }^{15}$ C-G Han, B-P Zhang, Z-H Ge, L-J Zhang, Y-C Liu, J. Mater. Sci. 48, 4081 (2013)

${ }^{16}$ G.M. Abramova, A.M. Vorotynov, G.A. Petrakovskii, N.I. Kiselev, D.A. Velikanov, A.F. Bovina, R.F. Al'mukhametov, R.A. Yakshibaev, É.V. Gabitov, Phys. Solid State 46, 2225 (2004)

${ }^{17}$ N. Le Nagard, G. Collin, O. Gorochov, Mat. Res. Bull. 14, 1411 (1979)

${ }^{18}$ R.F. Almukhametov, R.A. Yakshibayev, E.V. Gabitov, A.R. Abdullin, R.M. Kutusheva, Phys. Stat. Sol. (b) 236, 29 (2003) 
${ }^{19}$ The lattice parameters increase from $a=3.47962(2) \AA, c=18.6927(2)$ for an as-synthesised sample to $a=3.48038$ (3) $\AA, c=18.6969$ (2) $\AA$ for a cold-pressed and sintered sample.

${ }^{20}$ M.A. Boutbila, J. Rasneur, M.E. Aatmani, J. Alloys Comp. 283, 88 (1999)

${ }^{21}$ G.S. Nolas, M. Kaeser, R.T. Littleton, T.M. Tritt, Appl. Phys. Lett. 77, 1855 (2000)

${ }^{22}$ J. Garcia-Canadas, A.V. Powell, A. Kaltzoglou, P. Vaqueiro, G. Min, J. Elec. Mat. 42, 1369 (2013) 